\title{
The Structure, Process, and Outcome of Mentorship on Survivor with Schizophrenia: A Case Study
}

\author{
Rozali Arsyad Kurniawan', Suryani Suryani' ${ }^{2}$, Taty Hernawaty ${ }^{3}$, Lilibeth Al-Kofahy ${ }^{4}$ \\ ${ }^{1}$ Banyumas Regional Hospital, Central Java, Indonesia \\ 2,3Nursing Faculty, Universitas Padjadjaran, Bandung, Indonesia \\ ${ }^{4}$ Sam Houston State University, Texas, United States \\ Corresponding Email: rozali_arsyad82@yahoo.com
}

Received: 26-03-2021 Revised: 29-04-2021 Accepted: 30-04-2021

\begin{abstract}
The personal recovery paradigm in schizophrenia patients require a change of service. One of the changes that can be made to support the schizophrenia recovery process is a change in the concept of the relationship between patients and nurses. Nurse mentorship for schizophrenia patients is a new terminology of innovation in a supportive relationship between health workers and patients. At present, it is not known how the structure, process, and outcome of mentorship to schizophrenia survivors. This study aimed to explain how the structure, process, and outcome of mentoring nurses to schizophrenia survivors. This research is qualitative research using the case study method involving three cases of mentorship conducted in Banyumas Regional Hospital. A total of nine participants were involved in this study which consisted of three nurses as mentors, three schizophrenia survivors, and three caregivers. Data were collected by semi-structured interview techniques, observation, and document review. After in-depth analysis seven research themes were found. Participants' perception about the structure of mentorship include the theme mentorship requires a variety of abilities of nurses and conditions of survivors who can participate in mentorship. While the mentorship process includes the theme requires patience in mentorship, giving guidance for the recovery of survivors, and facing the recurrence of survivors due to treatment factors. Participants revealed the outcome of mentorship in the theme mentors feel inner satisfaction, and survivors feel more enthusiastic about life. The results of this study provide the view that mentorship has the potential to be developed into quality nursing interventions to support the recovery process of schizophrenia survivors.
\end{abstract}

Keywords: Case study, mentorship, schizophrenia recovery. 
Rozali Arsyad Kurniawan: The Structure, Process, and Outcome of Mentorship on Survivor with Schizophrenia

\section{Introduction}

Schizophrenia is a serious mental disorder that is most often found in society. According to $\mathrm{WHO}$, as many as 21 million people in the world suffer from schizophrenia (WHO, 2016). In Indonesia, based on the results of the 2018 Riskesdas the proportion of households with severe mental disorders (schizophrenia or psychosis) nationally is 7 per 1,000 households (Ministry of Health, 2018). Globally there has been a change in the concept of healing in mental patients (Korsbek, 2016). Whereas in the past the view of healing schizophrenia patients rests more on the view of "clinical recovery" which emphasizes symptom relief and a reduction in the recurrence rate, in recent years this concept has been replaced by the concept of "personal recovery". Personal recovery in mental health refers to the process of changing attitudes, values, feelings, goals, and skills and rebuilding one's integrity to live a satisfying life within the limitations caused by illness (Anthony, 1993; Deegan, 2003; Suryani, 2018). Changing the view from the concept of clinical recovery to personal recovery demands changes in inpatient care. Recovery-oriented services are a paradigm shift from clinical-oriented services that emphasize more on stabilization and reduction of clinical symptoms to valueoriented services and principles of patientcentered service (person center care) and involve individuals in the service process (personal involvement) (Waldemar, Arnfred, Petersen, \& Korsbek, 2015). The concept of personal recovery schizophrenia in Indonesia has not been widely applied in services. Based on the results of Nurhayati's research, Kusumah and Murwasuminar (2019) revealed that currently, the Community Mental Health Nursing $(\mathrm{CMHN})$ program is a program that helps recover schizophrenia survivors by making home visits as one of its activities. The CMHN program in Indonesia is currently not fully implemented due to several reasons, namely incomplete mental health policies and lack of research or the lack of use of evidence-based practice in the application of mental health services (Nurhayati, Kusumah, \& Murwasuminar, 2019). In Indonesian culture, especially Sundanese culture there is a philosophy of life that is in accordance with the concept of mentoring, namely "Silih Asih", "Silih Asah", and "Silih Asuh". "Silih asih" has the meaning loving each other and "silih asah" has the meaning of wanting to give knowledge. Then the "silih asuh" that has the meaning of guiding each other. The culture has become a philosophy that will be very meaningful when developed to help schizophrenia recovery process.

The coaching or mentoring approach is a form of relationship between patients and professionals who can facilitate the recovery process (Borg \& Kristiansen, 2004; Suryani, 2018). Mentorship is a concept that has long been known as an effort to increase one's capacity. Mentorship is hidden assistance (offline help) from mentors to mentees (mentoring participants) in making significant changes in knowledge, work or ways of thinking (Clutterbuck \& Megginson, 1999). There are several studies that prove the effectiveness of mentorship-based interventions from nurses to patients in improving the health conditions and quality of life of patients. Some of these studies include COPD patients (Cameron-Tucker et al., 2016), recovery patients with myocardial infarction (Terence John Frohmader, Lin, \& Chaboyer., 2016) and breast cancer metastatic patients (Ye et al., 2017). Based on a preliminary study conducted at the Integrated Mental Health Installation at Banyumas Hospital in December 2019, data were obtained that there was a mentorship-based activity with activities to provide guidance from nurses to post-hospitalized schizophrenia patients. The guidance program uses a mentorship approach as a new innovation for recoveryoriented schizophrenia. As an intervention innovation, nurse mentorship to schizophrenia survivors has never been evaluated for its quality. According to Donabedian (1988), to evaluate the quality of a health service one must pay attention to structure, processes and outcomes. This research article aims to determine the structure, process, and outcome of mentorship of nurses to survivors of schizophrenia. 
Rozali Arsyad Kurniawan: The Structure, Process, and Outcome of Mentorship on Survivor with Schizophrenia

\section{Method}

The research method used in this research is an explanatory case study. This method was chosen because the researcher wanted to emphasize the explanation and understanding of the structure, process and outcome (Donabedian, 1988) of the nurse's mentorship program for schizophrenia survivors in the real-life context (Polit \& Beck, 2004; Robson \& McCartan, 2016; Yin, 2017).

Participants and Research Settings

The unit of analysis in this study was a case of nurse mentorship to schizophrenia survivors in the Puntadewa community at Banyumas Hospital. Participants in this study included nurses as mentors, schizophrenia survivors as mentee in mentorship and caregivers. The sampling technique used in this study was purposive sampling. This research has received approval from the UNPAD research ethics committee with Ethics Approval Letter Number: 381 / UN6. KEP / EC / 2020. and from the Health Research Ethics Committee of Banyumas Hospital with a certificate of ethics worthy number: 085 / KEPK-RSUDBMS / III / 2020 dated March 26, 2020.

\section{Mentorship Process}

Nurses who become mentors have attended training and workshops on recovery, therapeutic communication techniques, coaching techniques, and mentoring for schizophrenia patients. Schizophrenia survivors in this study were schizophrenia patients who were undergoing an outpatient process at Banyumas General Hospital. Schizophrenia survivors who take part in the mentorship process are determined based on several considerations from the mentor, including the closeness of the relationship that has been previously established.

The mentorship process at the Puntadewa community begins by making an agreement between the mentor and the caregiver and schizophrenia survivor to undergo a mentorship program. The next step is that the nurse, together with the survivor and caregiver, is to explore the living conditions experienced by the survivors. The exploration includes conditions of family relationships, friendship, work, daily activities, spirituality, and education. After exploration, the mentor and the survivor discuss the goals and plans for achieving these goals.

The goals and achievement plans that have been prepared are mutually agreed upon between the survivor and the mentor. Survivor is committed to carrying out the plan that has been prepared. Caregivers are asked to assist and support the implementation of the agreed activities. At the next meeting, the mentor evaluated the implementation of the activities. The mentor and the survivor discussed the achievements and obstacles in carrying out the activities that have been determined. At this stage, the mentor provides support to the survivor, has a positive attitude, and acts constructively to help the survivor achieve the goal of recovery. If the previously set goals have been achieved, the mentor encourages the survivor to create new additional goals for his recovery. The termination of the mentorship process will be carried out when the stated goals have been achieved and both parties mutually agree to stop the mentorship process.

\section{Data analysis}

According to Miles and Huberman (2002), there are several stages of data analysis that are commonly used in case study research. The data analysis stage was preceded by data collection. At the data collection stage, researchers obtained information collected through interviews, observations, and document reviews. The three pieces of information are transcribed into sentences.

Data reduction is the first analysis step after data collection. This process includes data selection, focusing, simplifying, and abstraction of data that appear in observation notes, document review, and data transcription. At this stage, the researcher tried to appreciate the data by listening to the recorded conversations over and over again. Then, the researcher read the textual data that has been obtained repeatedly. Researchers classify data into patterns by emphasizing, shortening, focusing, and selecting and paraphrasing the data transcript into a code/ 
coding. Researchers conclude and combine codes that have the same pattern or have a relationship into a category. Then, from several categories that have been formed, the researcher analyzes and combines the same categories into a larger pattern, namely themes. Data collection and data reduction interact with each other by making conclusions and presenting data, there is reciprocal interaction and the development is sequential and interactive. This stage continues until the end of the analysis process.

The next stage is data presentation (data display). The data presentation stage is carried out after a number of data obtained are performed data reduction. This stage is done by arranging the information into an orderly arranged table of information. The purpose of presenting this data is done so that researchers get well-organized information in a form that is easily accessible and concise so that researchers can see what is happening and or make data conclusions. The last stage is to describe the conclusion and verification (conclusion drawing and verification). At this stage, the researcher makes conclusions and verification based on the data obtained. Researchers conducted a deductive analysis of the themes that had been formed using a framework of structure, processes and outcomes according to Donabedian (1988) to find out how these themes described the quality of health service interventions.

\section{Results}

Overall, there were nine participants involved in this study which included nurses as mentors, schizophrenia survivors, and caregivers of schizophrenia survivors. After conducting an in-depth analysis process, themes related to the structure, process and results of nurse's mentorship to schizophrenia survivors were obtained as follows:

\section{Structure of Mentorship for Schizophrenia Survivors}

According to Donabedian (1988), "structure" can be defined as the qualifications of service providers required, the equipment and equipment required and the resources required to carry out an intervention. The results of the analysis of this study found that structural elements including the theme of mentorship require a variety of abilities of nurses and conditions of survivors who can participate in mentorship. The following is a discussion of this theme.

\section{1) Mentorship Requires a Variety of Nursing} Abilities

This research reveals that mentorship requires a variety of abilities of nurses. Conceptually, mentorship is a relationship that involves two parties, namely someone who is considered more experienced / expert (mentor) and someone who is considered less experienced / beginner (mentee) to develop personal and professional abilities (Dancer, 2003).

The nurses who participated in this study had more than ten years of experience working in the area of mental nursing. This opinion was also conveyed by the nurse that one of the important things to become a mentor for survivors of schizophrenia is experience.

"And for sure we have to have the experience, we have long an experience in mental health, they really believe," (M03)

In this study, the participants believed that to become a mentor they needed to master mental nursing, psychology and apply therapeutic communication and update science.

"Indeed, the first is like in psychology which has been famous for so far, namely building trust relationship, yes ... the term is how we build trust first with patients or their families..." (M02)

Based on the observations, the mentor applies several therapeutic communication techniques during mentorship activities. This can be seen in the following observational data;

"The mentor and survivor seemed to laugh with humor conveyed by the mentor in between their conversation" (Obs 02)

"The mentor uses open-ende $\bar{d}$ questions when asking about the condition of the survivor". (Obs03)

According to participants, one of the skills a mentor considers necessary is the ability to analyze the problems at hand.

"... we explore the potential things that could cause that problem which may be 
needed here. So it is not just an asset to talk, but also to be able to analyze the facts. "(M02)

Participants also highlighted the mentor's ability to establish relationships with doctors in charge of patients, rehabilitation institutions and parties who can provide capital for survivors to work. According to the mentor, this ability is needed to help overcome the various challenges faced during the recovery process for schizophrenia survivors.

"We also have to have a relationship with related links related to rich mental nursing, like we have to have a relationship with people in the orphanage so that we can quickly access it when those we mentor need rich rehab" (M01)

\section{2) Conditions for Survivors Who Can Join Mentorship}

The results of this study found several conditions for survivors who could join the mentorship program. This research reveals that mentorship will be easier to do for survivors with good insight.

This opinion was expressed by the following participants;

"So if he is aware that" oh I have a psychotic disorder, "he realizes that the symptoms can appear without him knowing it ... he is aware of that, if he is aware, of course it's different when we give advice, if someone has a negative insight...huh ... doesn't feel sick anymore, continues to feel good, we just give advice, he can fight like that. " (M01)

This opinion is supported by the results of a document review, which shows that based on the mentorship document notes, the mentor's description explains the condition of the survivor's insight:

"Description of the condition of the mentee: communicative, good insight, lack of activity, feeling lazy to do activities" (Dok_01)

The next condition is schizophrenia survivors who often recur. According to participants, there are several factors that cause survivors to recur frequently, namely environmental conditions that are not supportive for survivor recovery, caregivers who do not know how to care for survivors of schizophrenia or economic factors that cause survivors to be at risk of withdrawal from drugs.

"It's time for the patient to be treated like that ... so in a condition where patients who often relapse usually need a mentorship approach.” (M02).

\section{Process of Mentorship for Schizophrenia Survivors}

According to the Donabedian framework (1988), "process" is how the intervention is carried out in providing services. The process includes how to build relationship skills, use skills and knowledge in service delivery. The results of this study reveal that the mentorship process includes the following themes;

\section{1) Requires Diligence in Conducting Mentorship}

The results of this study reveal that doing mentorship requires patience. Participant data shows that the mentorship process takes a long time and requires patience. This patience is especially true when facing changes in the condition of the survivors and the nature of schizophrenia recovery which requires a long period of time. As the participant's expression follows:

"At the time ... first, the initial guidance was still lacking ... the mental condition was still sometimes invited to my house. I was still "ndleming" (talking to myself. Ed), talking to myself, the view was still there ... well then after being diligent, yes ... for up to 2 years it's been very good, the communication is continuous. "(M01)

This study revealed that the mentor and survivor agreed on a mentorship meeting schedule. In this study, it was found that the mentorship meeting was held once a month at the same time as taking medication from the survivor. Meanwhile, according to survivors, they can meet with a mentor outside the agreed schedule if they feel there is a problem that needs to be conveyed to the mentor.

"Yes, when you meet every month you take the medicine. Then, for example, there is such a condition ... a problem that feels heavy or a problem with drugs that don't match, so I usually ask the sir ... (name of mentor). " (S01)

The results of the analysis also indicated that the mentor had a close relationship with the survivor. A close relationship can 
mean that both parties feel emotional and comfortable to live the relationship. This opinion is supported by the following observational data:

"Survivors and caregivers show not awkward behavior when talking with mentors // Survivors and caregivers use the language used in everyday life" (Obs_01)

Apart from building close relationships, the mentor also maintains the boundaries of the relationship with the survivor.

"But don't tell the dark side too much for example; (Saying) "I was also a drinker" for example. So you really have to be careful to know the limits where what should we tell and which ones we should keep first." (M03)

\section{2) Providing Guidance for Survivor Recovery \\ Research participants highlighted that} mentorship is an activity to provide guidance for survivor recovery. Some data support the theme of providing guidance for survivor recovery, namely mentors teaching survivors how to deal with schizophrenia symptoms. This can be seen from the following participant expressions;

"When the condition is good, the insight is good, I realize the communication is continuous, I will tell you about hallucinations ... yes, if here, the hallucination management is ..." (M01)

The findings of the data analysis indicated that the mentor used potential sources of support for recovery survivors. Support in the form of commitment from the family is needed during the mentorship process as revealed by the following mentor

"But when the family decided and say ; "okay sir, that I ask my son to be visited every month by Pak Dwi then what the doctor instructs us to try." (M02)

In addition to family support, the mentor also uses the potential that exists in the survivor and the conditions in the surrounding environment.

"What are you managing...the fish pond he said at home ... yes yes because in his environment he is a rice field ..." (M01)

The findings in this theme are mentors discussing the future of survivors to build survivor optimism. The following is the mentor's statement about discussing the future of the survivor;
"I convey for the enthusiasm ... for the future what you want, for example work ... especially work, you have to work, have a job or have activities later to get money then be happy." (M03)

\section{3) Confronting a Survivor Recurrence Due to Treatment Factors}

The results of this study identified that in conducting mentorship, mentors often face recurrence of survivors due to medical factors.

"So the point is stable, the drug is stable, it continues to stop ... because it feels stable, it stops and keeps relapses,". (M01)

The mentor revealed that during the mentorship process, the mentor provided psycho-educational interventions to increase medication adherence to reduce recurrence of schizophrenia survivors. This opinion is supported by the results of observational data showing that the mentor discussed the benefits of survivor treatment for recovery.

"Survivor asks the mentor about the drugs that are obtained, sometimes changing drugs // The mentor explains the treatment process and the drugs he is taking." (Obs_03)

\section{Outcome Mentorship for Schizophrenia Survivors}

The concept of "outcome" referred to by Donabedian (1988) is how the effect of the health services provided has an impact on the patient's health status.

The following is a discussion of this theme.

1) The mentor feels an inner satisfaction

The results of this study reveal the benefits of mentorship felt by nurses as mentors. Analysis of the results of interviews with the three mentors showed that they felt inner satisfaction after doing mentorship. A mentor said that there is a sense of satisfaction in being able to provide something useful for others even though it is only in the form of advice. The same thing was conveyed by other mentors that the mentor felt invaluable inner satisfaction when the survivor made progress in recovery. This opinion is as expressed by the following mentor;

"We have a sense of satisfaction, because we can provide something useful for others even though it's just advice. But when the 
Rozali Arsyad Kurniawan: The Structure, Process, and Outcome of Mentorship on Survivor with Schizophrenia

advice is carried out and it gives a positive result, we feel that there is a separate inner satisfaction ... thank God, our knowledge is very beneficial, there is a sense of inner satisfaction. "(M01)

In addition, another form of satisfaction felt by the mentor is increasing brotherly friendship and adding to the experience of the mentor. This opinion was supported by the survivor's statement which stated that the mentor stayed in touch with the survivor's place during Eid.

"He (mentor) when Eid comes here, bro, get along with him" (S02)

"It adds to our experience in handling patients because when we finish this case, there will definitely be other cases that we will have to solve that can eventually add insight, okay?” (M02)

2) Survivor Feeling Increased Spirit of Life

This research shows that mentorship has a positive impact on the recovery process for schizophrenia survivors. Researchers obtained subjective data about the benefits of mentorship based on the changes felt by survivors of schizophrenia. The results of the study revealed that survivors felt an increased enthusiasm for life during the mentorship process from the nurses. Participants stated that they were becoming more optimistic, able to control their emotions and felt excited to do positive activities.

"Sometimes there are problems with the family. For example, if I have a problem with my brother, it is not suitable or what about it, I sometimes confide in sir (name of mentor). " $(\mathrm{S} 02)$

This opinion was supported by the caregiver who saw the change in the survivor to become more able to control his emotions.

"Previously, sometimes sometimes when you say this loudly you can plaque you (playing hit) first .... if so, it's the same as Mbakyu. If it's not now ... it's weak isn't it. Now if I tell "diem", "(K03)

\section{Discussion}

Structure of Mentorship for Schizophrenia Survivors

1) Mentorship Requires a Variety of Nursing
Abilities

Experienced nurses have better work abilities because they have learned from the actions and problems they have faced. The work experience that nurses have in a particular field will shape the expertise in that field. A study on the work experience of nurses revealed that the work experience of nurses has a significant effect on nurses' performance. (Khandra, 2019). As identified by other studies, mentor friendliness, knowledge and ability in conveying information, open communication skills, active listening, and providing constructive feedback are needed to be a good mentor (Terence J Frohmader, Lin, \& Chaboyer, 2017; LaFleur \& White, 2010). In addition, establishing a therapeutic relationship is very important in supporting recovery to increase survivor cooperation and hope (Roberts \& Boardman, 2014).

McKimm, Jollie, and Hatter (2007) state that one of the values and principles in mentorship is the ability to reflect on past experiences. Mentors and mentees are expected to be able to identify and analyze previous experiences for future improvement (Dancer, 2003). Mentorship is not only seen as a problem-solving process, it is also a problem management process. The mentorship requires imagination and innovation to identify missed opportunities or potential that is not used by individuals so that these individuals can be more constructive in life, able to develop themselves and increase self-motivation (Dancer, 2003). Dancer (2003) states that the role of a mentor may change as the mentoring relationship develops and may include roles as a "networker" and a "connector". In this study, the mentor is expected to have a network and be able to become a liaison between the needs of recovery survivors and other appropriate parties. A study revealed the perspective of schizophrenia survivors that therapy must meet their needs for recovery in social functioning and personal growth contexts (Dilks, Tasker, \& Wren, 2010). This opinion is in accordance with the principle of holistic recovery, that is, apart from physical and psychological conditions. The recovery process must also pay attention to recovery supporting factors such as housing, employment, education and family (Bellack, 2006). Occupational problems in 
Rozali Arsyad Kurniawan: The Structure, Process, and Outcome of Mentorship on Survivor with Schizophrenia

survivors of schizophrenia are very common (Darsana \& Suariyani, 2020). According to McGurk, Mueser, DeRosa, and Wolfe, (2009) "working" for survivors of schizophrenia is closely related to the recovery process.

2) Conditions for Survivors Who Can Join Mentorship

The dimension of insight is one of the important factors affecting recovery parameters in schizophrenia patients (Mashiach-Eizenberg, Hasson-Ohayon, Yanos, Lysaker, \& Roe, 2013; Yanos, Roe, Markus, \& Lysaker, 2008). Poor insight is a very common phenomenon in schizophrenia where about $97 \%$ of patients with a first episode of the disease do not admit that their symptoms are related to the disease process (Soroka, Dziwota, Pawęzka, \& Olajossy, 2017). Improved insight can make patients realize the need to adhere to the principles of care, able to build and maintain long-term interpersonal relationships. This opinion is in accordance with a review which states that good insights are associated with positive outcomes, such as treatment adherence and better recovery (Cavelti, Kvrgic, Beck, Kossowsky, \& Vauth, 2012).

Schizophrenia survivors who often recur, according to the mentor, needs to be overcome by doing mentorship. Recurrence of schizophrenia has a negative impact and puts a burden on the patient, and affects the family directly or indirectly (Nurmaela, Suryani, \& RAfiyah, 2018). Aqualitative study involving schizophrenia patients revealed that participants suggested strengthening psychoeducation sessions, home visits and strengthening nurse-patient therapeutic relationships in providing care to help reduce recurrence of schizophrenia patients (Sariah, Outwater, \& Malima, 2014). This is in line with the opinion of Suryani (2018) who said that a supportive environment is needed for survivors to undergo the recovery process. Support from health workers, families and communities and the government can encourage survivors to find their strength based so that schizophrenia survivors can undergo a good recovery (Suryani, 2018).

\section{Proccess of Mentorship for Schizophrenia Survivors}

1) Requires Diligence in Conducting
Mentorship

A mentorship relationship is a special relationship where two people make a real connection with each other. In other words, they form bonds that are built on mutual trust and respect, openness and honesty in which each party can still be themselves (Dancer, 2003). A study revealed that a mentor must have a level of patience and understanding in guiding them to achieve their goals (HenryNoel, Bishop, Gwede, Petkova, \& Szumacher, 2019). Meanwhile, according to McKimm, Jollie, and Hatter (2007) mentorship is a long-term relationship process to achieve a goal that requires the patience of both parties. According to Bellack (2006), the recovery process is a non-linear process, meaning that recovery is not a series of sequential steps. One time the individual can experience progress in the recovery process, but at another time the individual experiences a recurrence or setback. Mentors who understand the principles of schizophrenia survivor recovery will understand that patience is needed in conducting mentorship because they will face various conditions for schizophrenia survivors.

According to McKimm, Jollie, and Hatter (2007) state that one of the qualities of a mentor is that the mentee must be easily accessible. Mentees can easily meet with mentors if at any time the mentee needs a mentor. The quality of the mentor-mentee relationship is very important to achieve mentorship goals, if the relationship does not occur and one or both parties feel uncomfortable in the relationship, the mentorship process will not be sustainable (McKimm, Jollie, \& Hatter, 2007). According to Roberts and Boardman (2014), one of the important domains to support recoverybased practice for schizophrenia patients is to support individuals and their families to fulfill their potential and shape their own future by establishing therapeutic relationships and increasing their involvement and increasing hope.

According to participants, this was done so that the advice or guidance given by the 
mentor could be accepted by the survivor as professional advice. Openess is one of the dimensions of action required in a therapeutic relationship. This opinion is in accordance with the opinion of Stuart (2014) which states that nurses' self-disclosure must be done carefully and have a therapeutic purpose. The benefits of nurses' openness can be used to increase cooperation, learning, catharsis and support (Stuart, 2014). The openness of the nurse that is not in accordance with the conditions currently being experienced by the client and the number of statements of openness that is too much from the nurse can make the client not have time to openly convey the problem he is experiencing (Stuart, 2014).

\section{2) Providing Guidance for Survivor Recovery} According to Suryani (2018), schizophrenia patients who undergo recovery need to receive guidance from a mentor so that survivors are enthusiastic and committed to carrying out the recovery process. This opinion is in line with Vance (1995) in Schaffer, M. A., and Mbibi, N. (2014) which states that a mentor has a role to maintain, encourage, guide, and act as a role model for mentees to behave healthily. Survivors who recover from schizophrenia often report that they are greatly helped by someone who believes in them in a mentorship relationship (Kelly \& Gamble, 2005). These results are in accordance with the results of research that the mentorship program was successfully used to guide patients with myocardial infarction recovery programs in improving health, patient welfare (Terence J Frohmader et al., 2017) and improving quality of life and medication adherence in the recovery process for patients with eating disorders (eating disorders) (Perez, Van Diest, \& Cutts, 2014).

According to Suryani (2018), a health worker must be able to see the potential that exists in society. Community empowerment can be done to develop potential in the community, develop community contributions in helping the recovery process for schizophrenia survivors. The recovery process requires support from various factors such as treatment, society, government and religious factors (Hamaideh, Al-Magaireh, Abu-Farsakh, \& Al-Omari, 2014). Research in Jordan reveals that social support such as support from friends or trusted people is the most influential domain for the quality of life for survivors of schizophrenia (Hamaideh et al., 2014).

Building survivor optimism in the recovery process in accordance with the framework in the mental disorder recovery process which includes aspects of Connectedness, Hope \& Optimism, Identity, Meaning in Life and Empowerment (CHIME) (Leamy, Bird, Le Boutillier, Williams, \& Slade, 2011). This opinion is also consistent with the results of research by Borg and Kristiansen (2004) which states that a relationship that fosters hope can help the recovery process for schizophenic patients. Hope in the characteristics of recovery means self-confidence to get a better future by overcoming problems and obstacles that occur. Hope is a key component in the recovery process for schizophrenia survivors. (Frese III, Knight, \& Saks, 2009).

\section{3) Confronting a Survivor Recurrence Due to Treatment Factors}

Non-adherence to taking medication is a problem that often occurs in schizophrenia patients (Barkhof, Meijer, de Sonneville, Linszen, \& de Haan, 2012). A study revealed that $62.1 \%$ of the 95 schizophrenia patients relapsed due to treatment non-adherence (Singh, Karmacharya, \& Khadka, 2019). According to qualitative research involving schizophrenia patients, it was found that one of the causes of recurrence in schizophrenia patients was due to non-compliance with treatment (Amelia \& Anwar, 2013). A study states that doing psychoeducation accompanied by a combination of work alliances such as improving the relationship between service providers and patients is proven to be more effective in increasing patient medication adherence (Phan, 2016). Another study involving 72 schizophrenia patients revealed that the therapeutic relationship between health care providers and schizophrenia patients is a strong predictor of treatment adherence in schizophrenia patients (Tessier et al., 2017). 


\section{Outcome Mentorship for Schizophrenia Survivors}

1) The mentor feels an inner satisfaction

Mentorship relationships that have been established for a long time can add to a wider friendship. Unlike other relationships, mentorship usually deals with problems that may overlap with personal and professional boundaries (Dancer, 2003) so that mentors and mentees feel the closeness of their relationship. Wolak et al. (2009) who examined mentorship in the area of nurse education reported that most of the mentors in the mentorship program they studied expressed feelings of happiness seeing their mentee develop as a nurse. The findings of this study support mentorship research for patients with myocardial infarction rehabilitation (Terence J Frohmader et al., 2017) and patients with chronic obstructive pulmonary disease (Wood-Baker, Reid, Robinson, \& Walters, 2012), where the nurse as a mentor expresses satisfaction when the client able to make lifestyle changes that are healthier for the disease. A systematic review also reveals the positive impact mentorship has on mentors personally and practically, personal satisfaction, professional success, and contributions to the organization and the profession (LaFleur \& White, 2010).

2) Survivor feeling the increased spirit of life

These results are in line with several studies which reveal that mentorship programs for patients can have a positive impact on the patient's recovery process. The results of a case study in Australia regarding nurse mentorship to patients with myocardial infarction showed an increase in quality of life, decreased anxiety and increased physical activity ability of patients (Terence John Frohmader et al., 2016). Research conducted on women with metastatic breast cancer in China found that mentorship-based programs can significantly reduce emotional distress (anxiety, depression, etc.), improve quality of life and patient resilience (Ye et al., 2017). In addition, participants in the study also revealed that feelings of empowerment emerged, especially in increasing selfconfidence and hope (Ye et al., 2017).

Some of the participants felt happy because they had a place to address their problems during the recovery process and got solutions from mentors. According to Fertman and Allensworth (2016) mentorship is a health promotion by engaging in interpersonal relationships using social support theory. Social support is all forms of assistance or things given by people in their social environment that can provide emotional benefits or influence the behavior of the recipient (Fertman \& Allensworth, 2016). In this mentorship process, the mentor shows a sense of empathy, care and positive appreciation and encouragement for schizophrenia survivors, which is a form of emotional support from the mentor. Someone who gets emotional support will create a sense of comfort, togetherness, a feeling of belonging and being loved when facing stressful situations (Sarafino \& Smith, 2014).

\section{Conclusion}

Research in Indonesia has not explored the mentorship of nurses to schizophrenia survivors. The lack of information regarding mentorship for schizophrenia survivors makes the results of this study provide important information for nursing science. The nursing implication of the results of this study is that nurses are expected to increase experience in managing schizophrenia patients and increase knowledge and skills of evidencebased schizophrenia patient care. In carrying out mentorship for schizophrenia survivors, nurses must be patient in conducting mentorship for schizophrenia survivors. Nurses' skills in using various abilities are needed to help schizophrenia survivors in overcoming the challenges of schizophrenia recovery. In addition to providing benefits to the schizophrenia survivor recovery process, mentorship can also provide a feeling of inner satisfaction for nurses as mentors.

Nurse mentorship approach to schizophrenic patients is in accordance with the service principle of "patient centered care" in a mental hospital. In summary, nurse mentorship for schizophrenia survivors can be developed in a mental hospital as a clinical care practice as well as a home care service.

The mentorship approach is a new 
Rozali Arsyad Kurniawan: The Structure, Process, and Outcome of Mentorship on Survivor with Schizophrenia

innovation that has the potential to be developed into an inpatient nursing practice in mental hospital and later integrated in Community Mental Health Nursing (CMHN) to help the recovery process for schizophrenia survivors. The development of mentorship interventions for schizophrenia survivors in the community needs support from policy makers so that nurses can provide patient centered care and ensure continuity of care for schizophrenia survivors.

\section{References}

Amelia, D. R., \& Anwar, Z. (2013). Relaps pada pasien skizofrenia. Jurnal Ilmiah Psikologi Terapan, 1(1), 53-65. https://doi. org/10.22219/jipt.v1i1.1357

Anthony, W. A. (1993). Recovery from mental illness: the guiding vision of the mental health service system in the 1990s. Psychosocial Rehabilitation Journal, 16(4), 11-23. https://psycnet.apa.org/doi/10.1037/ h0095655

Barkhof, E., Meijer, C. J., de Sonneville, L. M., Linszen, D. H., \& de Haan, L. (2012). Interventions to improve adherence to antipsychotic medication in patients with schizophrenia-a review of the past decade. European Psychiatry, 27(1), 9-18. https:// doi.org/10.1016/j.eurpsy.2011.02.005

Bellack, A. S. (2006). Scientific and consumer models of recovery in schizophrenia: concordance, contrasts, and implications, 32(3), 432-442. https://doi.org/10.1093/ schbul/sbj044

Borg, M., \& Kristiansen, K. (2004). Recoveryoriented professionals: Helping relationships in mental health services. Journal of Mental Health, 13(5), 493-505. https://psycnet.apa. org/doi/10.1080/09638230400006809

Cameron-Tucker, H. L., Wood-Baker, R., Joseph, L., Walters, J. A., Schüz, N., \& Walters, E. H. (2016). A randomized controlled trial of telephone-mentoring with home-based walking preceding rehabilitation in COPD. International Journal of Chronic
Obstructive Pulmonary Disease, 25(11), 1991-2000. https://doi.org/10.2147/copd. s109820

Cavelti, M., Kvrgic, S., Beck, E.-M., Kossowsky, J., \& Vauth, R. (2012). Assessing recovery from schizophrenia as an individual process. A review of self-report instruments. European Psychiatry, 27(1), 19-32. https:// doi.org/10.1016/j.eurpsy.2011.01.007

Clutterbuck, D., \& Megginson, D. (1999). Mentoring executives and directors. Routledge.

Dancer, J. M. (2003). Mentoring in healthcare: theory in search of practice?. Clinician in Management, 12(1), 21-31.

Darsana, I. W., \& Suariyani, N. L. P. (2020). Trend Karakteristik Demografi Pasien Sskizofrenia Di Rumah Sakit Jiwa Provinsi Bali (2013-2018). Health, 41. (Demographic Characteristic Trends of Schizophrenic Patients In Bali Provincial Mental Hospitals). https://doi.org/10.24843/ACH.2020.v07.i01. p05

Deegan, G. (2003). Discovering recovery. Psychiatric Rehabilitation Journal, 26(4), 368-376. https://psycnet.apa.org/ doi/10.2975/26.2003.368.376

Dilks, S., Tasker, F., \& Wren, B. (2010). Managing the impact of psychosis: A grounded theory exploration of recovery processes in psychosis. British Journal of Clinical Psychology, 49(1), 87-107. https:// doi.org/10.1348/014466509x439658

Donabedian, A. (1988). The quality of care: how can it be assessed? Jama, 260(12), 1743-1748. jama.260.12.1743

Fertman, C. I., \& Allensworth, D. D. (2016). Health promotion programs: from theory to practice. John Wiley \& Sons.

Frese III, F. J., Knight, E. L., \& Saks, E. (2009). Recovery from schizophrenia: With views of psychiatrists, psychologists, and others diagnosed with this disorder. Schizophrenia 
Rozali Arsyad Kurniawan: The Structure, Process, and Outcome of Mentorship on Survivor with Schizophrenia

Bulletin, 35(2), 370-380. https://dx.doi. org/10.1093\%2Fschbul\%2Fsbn 175

Hamaideh, S., Al-Magaireh, D., AbuFarsakh, B., \& Al-Omari, H. (2014). Quality of life, social support, and severity of psychiatric symptoms in $\mathrm{J}$ ordanian patients with schizophrenia. Journal of Psychiatric and Mental Health Nursing, 21(5), 455-465. https://doi.org/10.1111/jpm.12112

Henry-Noel, N., Bishop, M., Gwede, C. K., Petkova, E., \& Szumacher, E. (2019). Mentorship in medicine and other health professions. Journal of Cancer Education, 34(4), 629-637. https://doi.org/10.1007/ s13187-018-1360-6

Kelly, M., \& Gamble, C. (2005). Exploring the concept of recovery in schizophrenia. Journal of Psychiatric and Mental Health Nursing, 12(2), 245-251. https://psycnet.apa. org/doi/10.1111/j.1365-2850.2005.00828.x

Kemenkes, K. K. I. (2018). Hasil utama riskesdas 2018. Kemenkes RI.

Khandra, S. (2019). Pengaruh Pengalaman Kerja, Kompetensi Dan Komitmen Organisasi Terhadap Kinerja Perawat Rawat Inap RST Wijayakusuma Purwokerto. Universitas Muhammadiyah Purwokerto. (Influence of Work Experience, Competence and Organizational Commitment to The Performance of Inpatient Nurses RST Wijayakusuma Purwokerto.). [Bachelor's thesis, Universitas Muhammadiyah Purwokerto], Repository UMP. Retrieved December 19, 2020, from http://repository. ump.ac.id/9798/1/Syafri\%20Khandra JUDUL.pdf

Korsbek, L. (2016). Corecovery: Mental health recovery in a dynamic interplay between humans in a relationship. American Journal of Psychiatric Rehabilitation, 19(3), 196-205. https://psycnet.apa.org/doi/10.108 0/15487768.2016.1197863

LaFleur, A. K., \& White, B. J. (2010). Appreciating mentorship: the benefits of being a mentor. Professional Case Management, 15(6), 305-311. https://doi.org/10.1097/ ncm.0b013e3181eae464
Leamy, M., Bird, V., Le Boutillier, C., Williams, J., \& Slade, M. (2011). Conceptual framework for personal recovery in mental health: systematic review and narrative synthesis. The British Journal of Psychiatry, 199(6), 445-452. https://doi.org/10.1192/bjp. bp. 110.083733

Mashiach-Eizenberg, M., Hasson-Ohayon, I., Yanos, P. T., Lysaker, P. H., \& Roe, D. (2013). Internalized stigma and quality of life among persons with severe mental illness: The mediating roles of self-esteem and hope. Psychiatry Research, 208(1), 15-20. https:// doi.org/10.1016/j.psychres.2013.03.013

McGurk, S. R., Mueser, K. T., DeRosa, T. J., \& Wolfe, R. (2009). Work, recovery, and comorbidity in schizophrenia: a randomized controlled trial of cognitive remediation. Schizophrenia Bulletin, 35(2), 319-335. https://doi.org/10.1093/schbul/sbn182

McKimm, J., Jollie, C., \& Hatter, M. (2007). Mentoring: Theory and practice. NHSE.

Nurhayati, G. E., Kusumah, R. B., \& Murwasuminar, B. (2019). The experiences of stakeholders in supporting the implementation of the mental health community recovery program in West Java Province Indonesia. Belitung Nursing Journal, 5(6), 225-233.

Nurmaela, N. M., Suryani, S., \& Rafiyah, I. (2018). The relation of the family resilience with substance on skizofrenia patients in the psikiatri unit. Jurnal Keperawatan Padjadjaran, 6(1). https://doi.org/10.33546/ bnj.618

Perez, M., Van Diest, A. K., \& Cutts, S. (2014). Preliminary examination of a mentorbased program for eating disorders. Journal of Eating Disorders, 2(1), 24. https://dx.doi. org/10.1186\%2Fs40337-014-0024-0

Phan, S. V. (2016). Medication adherence in patients with schizophrenia. The International Journal of Psychiatry in Medicine, 51(2), 211-219. https://doi. org/10.1177/0091217416636601

Polit, D. F., \& Beck, C. T. (2004). Nursing 
Rozali Arsyad Kurniawan: The Structure, Process, and Outcome of Mentorship on Survivor with Schizophrenia

research: Principles and methods. Lippincott Williams \& Wilkins.

Roberts, G., \& Boardman, J. (2014). Becoming a recovery-oriented practitioner. Advances in Psychiatric Treatment, 20(1), 37-47. https:// doi.org/10.1192/apt.bp.112.010652

Robson, C., \& McCartan, K. (2016). Real world research. John Wiley \& Sons.

Sarafino, E. P., \& Smith, T. W. (2014). Health psychology: Biopsychosocial interactions. John Wiley \& Sons.

Schaffer, M. A., \& Mbibi, N. (2014). Public health nurse mentorship of pregnant and parenting adolescents. Public Health Nursing, 31(5), 428-437. https://doi.org/10.1111/ phn. 12109

Sariah, A. E., Outwater, A. H., \& Malima, K. I. (2014). Risk and protective factors for relapse among individuals with schizophrenia: a qualitative study in Dar es Salaam, Tanzania. BMC Psychiatry, 14(1), 1-12. https://doi. org/10.1186/s12888-014-0240-9

Singh, P., Karmacharya, S., \& Khadka, S. (2019). Severity Of Relapse And Medication Adherence In Patient Of Schizophrenia: A Study From Nepal. Journal of Psychiatrists' Association of Nepal, 8(2), 54-58. http:// dx.doi.org/10.3126/jpan.v8i2.28027

Soroka, E., Dziwota, K., Pawęzka, J., \& Olajossy, M. (2017). Insight and recovery and the stigma of mental illness-analysis of the phenomenon of insight in schizophrenia and its correlations with the processes of stigma and self-stigma. Current Problems of Psychiatry, 18(4), 313-320. https://doi. org/10.1515/cpp-2017-0024

Stuart, G. W. (2014). Principles and practice of psychiatric nursing-e-book: Elsevier Health Sciences.

Suryani, S. (2018). Recovery Pada Skizofrenia (Vol. 1). Unpad Press.

Tessier, A., Boyer, L., Husky, M., Baylé, F., Llorca, P.-M., \& Misdrahi, D. (2017). Medication adherence in schizophrenia:
The role of insight, therapeutic alliance and perceived trauma associated with psychiatric care. Psychiatry Research, 257, 315-321. http://dx.doi.org/10.1016/j. psychres.2017.07.063

Waldemar, A. K., Arnfred, S. M., Petersen, L., \& Korsbek, L. (2015). Recovery-oriented practice in mental health inpatient settings: A literature review. Psychiatric Services, 67(6), 596-602. https://doi.org/10.1176/appi. ps.201400469

World Health Organization [WHO]. (2016). mhGAP intervention guide for mental, neurological and substance use disorders in non-specialized health settings: mental health Gap Action Programme (" mhGAP)! version 2.0: World Health Organization.

Wolak, E., McCann, M., Queen, S., Madigan, C., \& Letvak, S. (2009). Perceptions within a mentorship program. Clinical Nurse Specialist, 23(2), 61-67. https://doi. org/10.1097/nur.0b013e31819971eb

Wood-Baker, R., Reid, D., Robinson, A., \& Walters, E. H. (2012). Clinical trial of community nurse mentoring to improve self-management in patients with chronic obstructive pulmonary disease. International Journal of Chronic Obstructive Pulmonary Disease, 7, 407-413. https://doi.org/10.2147/ copd.s32220

Yanos, P. T., Roe, D., Markus, K., \& Lysaker, P. H. (2008). Pathways between internalized stigma and outcomes related to recovery in schizophrenia spectrum disorders. Psychiatric Services, 59(12), 1437-1442. https://doi.org/10.1176/appi.ps.59.12.1437

Ye, Z. J., Qiu, H. Z., Liang, M. Z., Liu, M. L., Li, P. F., Chen, P., .. . Zhang, Z. (2017). Effect of a mentor-based, supportive-expressive program, Be Resilient to Breast Cancer, on survival in metastatic breast cancer: a randomised, controlled intervention trial. British Journal of Cancer, 117(10), 14861494. https://doi.org/10.1038/bjc.2017.325

Yin, R. K. (2017). Case study research and applications: Design and methods: Sage publications. 